\title{
The effect of pulmonary rehabilitation on perceptions of breathlessness and activity in COPD patients: a qualitative study
}

\author{
*Veronika Williams ${ }^{a}$, Anne Bruton ${ }^{b}$, Caroline Ellis-Hill ${ }^{b}$, Kathryn McPherson \\ a School of Health and Social Care, University of Reading, Reading, UK \\ ${ }^{\mathrm{b}}$ School of Health Sciences, University of Southampton, Southampton, UK \\ c Division of Rehabilitation and Occupation Studies, Auckland University of Technology, Auckland, New Zealand
}

Received 24th February 2009; revised version received 10th April 2009; accepted 4th May 2009; online 14th July 2009

\begin{abstract}
Aim: The aim of this study was to explore, using qualitative research methods, how pulmonary rehabilitation (PR) programmes affect the experience of activity and breathlessness of people with COPD.

Methods: A qualitative, interview-based approach was employed. Participants were interviewed pre- and post-PR. Data were analysed using systematic strategies informed by grounded theory methods.

Results: Nine participants (three female) took part. A change in participants' perception of breathlessness and lessening of fear of activity were the main themes identified. PR appeared to impact on the experience of physical social activities, allowing participants to overcome feelings of social isolation.

Conclusions: Prior to PR, participants associated activities with breathlessness and panic; post PR, participants reported reduced fear and felt able to increase their activities. These findings add to our understanding of the impact of PR on individuals' experience of activity and may contribute to improved programmes by addressing patients' needs.

(C) 2010 Primary Care Respiratory Society UK. All rights reserved.

$\checkmark$ Williams, et al. Prim Care Resp J 2010; 19(1): 45-51.

doi:10.4104/pcrj.2009.00044
\end{abstract}

Keywords COPD, pulmonary rehabilitation, qualitative, patient experience, activity, breathlessness

The full version of this paper, with online Appendix,

is available at www.thepcrj.org

\section{Introduction}

Chronic obstructive pulmonary disease (COPD) is a leading cause of morbidity and mortality worldwide. It has been estimated that due to under-diagnosis of this condition there may be as many as 3.5 million people living with COPD in the UK. ${ }^{1}$ Pulmonary rehabilitation (PR) is a non-pharmacological intervention which aims to reduce disability in people with lung disease, return them to their highest level of independent functioning, and improve their quality of life..$^{2-4}$

One aspect of daily life often adversely affected by COPD is activity, including both physical and social activity. ${ }^{5-7}$ PR programmes aim to increase physical activity, and their success is frequently measured using quantifiable outcomes. However, improvements in such tests do not necessarily translate into altered activity patterns. ${ }^{8}$ In order to enhance our understanding of this mismatch, we need to know more about the impact of PR programmes on COPD patients' experience of activity from their individual perspective. This would allow us to provide interventions that address patients' needs and which are meaningful to patients. This may also improve patients' adherence - which is known to be low in this area $a^{9,10}$ - and therefore enhance positive outcomes. The aim of this study therefore was to explore how PR programmes affect the experience of activity of people with COPD, employing qualitative research methods.

\footnotetext{
* Corresponding author: Dr Veronika Williams, School of Health and Social Care, University of Reading, Bulmershe Court, Reading, RG6 1HY, UK Tel: +44 (0)1183786813 Fax: +44 (0)1183786808 E-mail: v.m.williams@reading.ac.uk
} 


\section{Methods}

Semi-structured interviews were used to collect data from COPD patients before and after a pulmonary rehabilitation programme. A qualitative, inductive approach informed by grounded theory methods"11 was chosen. This approach involves specific methods associated with recruitment, data collection and analytical procedures to develop themes inductively derived from data and allowed the researcher to focus on areas of interest throughout the simultaneous collection and analysis of data. ${ }^{12}$

\section{Participants}

The PR programme coordinator sent information leaflets about the study to patients with COPD on the PR waiting list. Exclusion criteria were: respiratory disease other than COPD; patients with co-morbidities; and patients who had been discharged from hospital within the last two weeks - in order to avoid recruiting people who were recovering from an acute illness or exacerbation. In total, 17 patients were invited to take part in the study, 12 of whom expressed interest. Of these, two did not meet the criteria and one decided not to take part after the initial contact. Therefore, nine patients with COPD took part in the study.

\section{The pulmonary rehabilitation programme}

The PR programme consisted of an eight-week long programme of two sessions (each lasting 1.5 hours) twice a week. It comprised physiotherapy including physical exercise components, occupational therapy including relaxation techniques, and educational sessions on various aspects of the condition such as oxygen therapy issues, inhaler technique and energy conservation.

\section{Data collection}

All participants provided written consent prior to data collection. Data were collected using face-to-face audiotaped interviews on two occasions (before and after PR), which took place at the participant's home. These were carried out by one of the authors (VW) who had previously worked within respiratory medicine but who was not associated with the PR programme itself; the relationship between the interviewer and the participant affects the way in which data are collected, but acknowledgment of these influences through reflexivity can enhance both the data collection and analysis processes. ${ }^{13}$

During the pre-PR interviews, questions focused around the individual's experience of activity. An interview schedule (see Appendix 1, available at www.thepcrj.org) was used to guide the interview, though participants were given the opportunity to talk about issues particularly important to them. The interview schedule was revised as the interviews proceeded to allow the researcher to explore issues identified in previous interviews further. The questions during the postPR interview explored the extent to which the PR programme had influenced the experience of activity. Field notes were written after each interview.

\section{Data analysis}

Interviews were transcribed verbatim and a qualitative software package was used to organise and store data $\left(\mathrm{NVivo}^{\circ}\right)$. Data were analysed using line by line coding and/or key phrases, thus creating shorter code phrases for each interview (open coding). ${ }^{14}$ Codes were created to summarise a particular section of data. Once all data were coded during this phase of open coding, axial (the process of relating codes and categories to each other) and selective (identifying core categories and themes) coding strategies were used to form categories and themes. ${ }^{11}$ Memo-writing (a way of exploring codes and categories during analysis) was used to explore similarities, differences and theoretical links between categories and themes across interviews. Constant comparison, a distinct feature of grounded theory, ${ }^{11}$ was used to compare codes and categories with new data which influenced further data collection by amending interview schedules in order to explore specific theoretical links.

\section{Ethical approval}

Ethical approval for this study was granted by the Oxford Radcliffe Hospitals Local Research Ethics Committee (Ethics no. 04/Q1702/103) prior to recruitment.

\section{Results}

One of the subjects was unable to complete the PR programme due to an exacerbation of COPD, so eight participants (three female) completed the programme. Their ages ranged from 54-84 years old (see Table 1). All were married and lived in their own homes with their spouses. At the time of the first interview, three were in full time employment, one worked on a part time basis, three had been retired for more than ten years, and two had taken early retirement on grounds of ill-health.

\section{Impact of PR on the perception of breathlessness}

The most important impact of PR on the experience of activity described by participants was a change in their perception of breathlessness - this was related to increased confidence in managing breathlessness and a loss of fear of activity. Figure 1 provides a model derived from the data, which is designed to illustrate the perceived impact of a PR programme on the experience of activity and breathlessness in COPD.

\section{- Experience of breathlessness: increased confidence}

Post-PR, participants reported a greater sense of confidence in managing their breathlessness and talked about how their feelings had changed from unacceptable fear and panic to a level that was acceptable to them. Although they still experienced the same breathlessness post-PR as before, the way they perceived their breathlessness had changed.

One patient who had very severe COPD and was unable 
Pulmonary rehabilitation, activity and COPD

\begin{tabular}{|c|c|c|c|c|c|c|c|c|}
\hline Pts & $\begin{array}{l}\text { Age } \\
\text { (Yrs) }\end{array}$ & Gender & Employment & Living set up & $\begin{array}{l}\text { Disease } \\
\text { severity }\end{array}$ & $\begin{array}{l}\text { Disease } \\
\text { length }\end{array}$ & $\begin{array}{l}\text { Oxygen } \\
\text { therapy }\end{array}$ & Nebuliser \\
\hline 1 & 64 & $\mathrm{~F}$ & Part time & Living with spouse & Severe & $\sim 8$ yrs & $N$ & $\mathrm{~N}$ \\
\hline 2 & 64 & M & Full time & Living with spouse & Moderate & $\sim 10 \mathrm{yrs}$ & $\mathrm{N}$ & Y \\
\hline 3 & 59 & M & Retired & Living with spouse & Severe & $>5 y r s$ & $N$ & $\mathrm{~N}$ \\
\hline 4 & 84 & M & Retired & Living with spouse & Very severe & $>10$ yrs & Y & Y \\
\hline 5 & 58 & $\mathrm{~F}$ & Full time & Living with spouse & Moderate & $>5 y r s$ & $\mathrm{~N}$ & $\mathrm{~N}$ \\
\hline 6 & 54 & $\mathrm{~F}$ & Full time & Living with spouse & Moderate & $\sim 5$ yrs & $\mathrm{N}$ & Y \\
\hline 7 & 77 & M & Retired & Living with spouse & Severe & $>10$ yrs & $\mathrm{N}$ & $\mathrm{N}$ \\
\hline 8 & 61 & M & Retired & Living with spouse & Severe & $>5$ yrs & $\mathrm{N}$ & $\mathrm{N}$ \\
\hline 9 & 70 & M & Retired & Living with spouse & Severe & $>10$ yrs & $\mathrm{N}$ & $\mathrm{N}$ \\
\hline
\end{tabular}

Figure 1. Perceived impact of pulmonary rehabilitation.
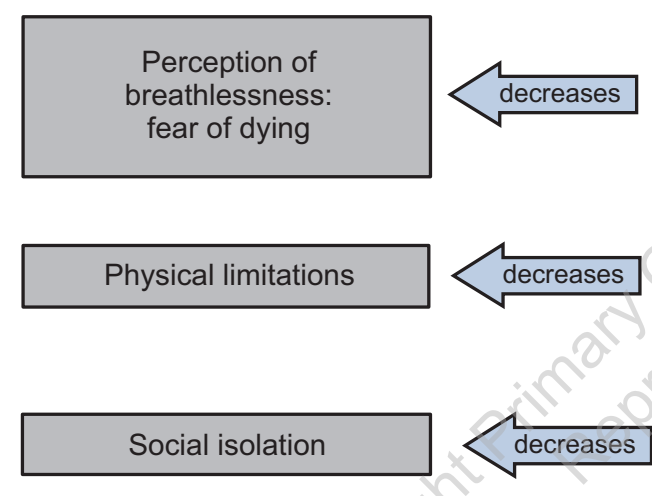

Pulmonary rehabilitation

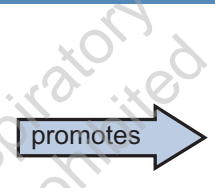

Perception of

breathlessness:

a. confidence in managing breathlessness

b. Loss of fear of activity

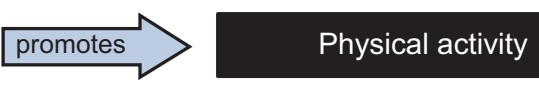

to walk more than 30 metres, felt more confident in dealing with breathlessness:

'I wouldn't say better in breathing you know cause that's still [a problem], but better in myself like, more confident, they have given me more confidence...' (Pt 4.2; 4-6)

Not only did participants feel more confident in dealing with their breathlessness, they also reported an increase in perceived control over their breathing:

'one of the things that I have learned is that to get out of breath a little bit is good ... I think I got a fear before that if I got out of breath I was gonna get into trouble but I think now I can I can control my limitations on that and I think that is really good' (Pt3.2; 22-28)

This patient had learned during the PR programme that breathlessness is not intrinsically bad. This impacted on the meaning of breathlessness to him, so he no longer experienced panic and anxiety, which ultimately impacted on his experience of activity.
- Loss of fear of activity

One aspect closely linked to increased confidence in dealing with breathlessness post-PR was a loss of fear of activity. The change from perception of breathlessness as a source for concern appeared to be associated with increased activity levels.

During her second interview, this patient talked about how she felt less worried about activities such a climbing stairs:

'I go to work, well, instead of using the lift now, I'm using the stairs and I'm talking well, my flat is 4 storeys up and there is several stairs actually you know and I'm walking up and down them, which is quite a thing because before I always used the lift [before] I was worried' (Pt 1.2; 92-97)

Prior to taking part in PR, participants had experienced anxiety and panic when breathless and were worried about engaging in physical activities which might exacerbate their breathlessness. PR appeared to alter their attitude to dyspnoea which allowed them to engage more in physical activities. 


\section{Impact on the experience of physical activities}

Taking part in a PR programme had an impact on participants' experience of activities on a physical level. Pre-PR they talked about their physical limitations, whereas post-PR they talked more about physical abilities. This impact on their experience of physical activity was apparent in two areas: physical mobility and work around the house.

- Effect on physical mobility

Pulmonary rehabilitation had an effect on how participants experienced activities related to physical mobility. One patient did very little walking prior to the PR programme as he found it too difficult, mainly due to his breathlessness:

'I walk to the shop which takes me, which is about 15, 20 minute walk away and I walk back but the thing is I can't walk back with a load of shopping ...it's not very good, yes, I usually take the car' (Pt 9.1; 205-212).

However, after the PR programme, he explained how he now walked everyday to the shops and even increased his physical activities by walking longer distances as well as going to the gym:

'but now I walk, ... I go all the way around the village and come in the other side, which takes me about 20 minutes, so it's 20 minutes walk I have every day, which is something I never used to do before' (Pt8.2; 123-129)

Taking part in a PR programme had a very positive impact on individual experience of physical activities and increased levels of mobility.

- Effect on household-related activities

Participants also talked about the impact of PR on householdrelated activities. These included activities inside the house and activities in the garden. Pre-PR, participants described their difficulties with such activities; however, during post-PR interviews, they explained how this experience had changed.

During the pre PR interview one patient explained how she found it difficult to do any heavy housework and was reliant on her husband to help with housework such as vacuum-cleaning:

'I can't hoover eh, if I hoover I'm, that's me finished. I mean if I didn't have my husband I don't know what I'd do..., I mean just dusting, I get out of breath, you know, it's hard to believe ... I can't garden, I can't mow the grass, even with an electric mower' (Pt1.1; 31-34; 47-49)

Post-PR she explained how her limitations had changed to abilities whereby she was now able to carry out more household activities that required physical effort and was less reliant on her husband:

'...I'm doing my own hoovering which I wasn't doing because he did it, I'm cleaning windows, which he did, I do, you know there is, yeah, definitely sharing the jobs more' (Pt1.2; 72-75)

This effect of PR on her experience of physical activities may have also led to her regaining her family role.

Similarly, this patient had been an enthusiastic gardener, but his COPD had resulted in his wife doing most of the gardening activities. Pre-PR he said:

.... used to take a great pride in my garden and for the last couple of years... my wife had just taken over basically grass cutting and I've totally neglected the garden' (Pt3.1; 2126)

Post-PR he described still experiencing limitations in physical activities, but being able to do more both inside and outside the house:

'... definitely doing more than I was ...... I mean before that I hadn't cut the grass for two years, my wife was doing it, I must admit I'm not doing it all the time now but I will go out and have a little bit of a go' (Pt3.2; 56-58; 79-81)

PR therefore not only had an impact on his experience of physical activity but also led to a resumption of a former role within his family.

\section{Impact on the experience of social activities}

As well as physical activity, PR also had a perceived impact on participants' social activity. Attending PR provided social support and an opportunity for social interaction. It was also associated with people undertaking activities outside of PR sessions which allowed them to overcome feelings of social isolation and increase their social activities.

\section{- Overcoming feelings of social isolation}

In this group of patients, feelings of social isolation were apparent in two ways: perceived lack of social support and understanding from others; and feeling housebound. During his second interview this patient explained how he used to feel alone with his problems and how PR had affected these feelings:

'I think just support from one another and being able to talk to other people about problems, ... I know there are a lot of other people around with the same problem but you don't always meet them, and you can feel you're the only one with the problem, and nobody understands but being together in a group like that you know it's like self support and you can talk to one another' (Pt 3.2; 30-35)

Another patient had very severe COPD and used home oxygen therapy. During the first interview he talked about being unable to leave the house prior to the PR programme. He would spend all his time indoors watching TV:

'[l do] nothing really, only stopping in the house really and listen to the radio and television' (Pt4.1; 37-38)

However, post-PR he said:

'...they have given me more confidence by being with people and going out twice a week for about 3/4 hours, go there and come back you know, and meet people' ...' it was lovely and we got on well,... and I used to look forward to meeting them and tell a few jokes and making them laugh you know' (Pt4.2; 5-7; 64-68) 
Taking part in a PR programme gave individuals more confidence to leave the home and socialise with other people, escaping feelings of being housebound.

Increase in social activities

Prior to the PR programme, participants talked about having given up certain social activities. Although many activities related to physical aspects, such as dancing and exercising, participants talked about these with regard to their social context.

One patient explained how she used to go dancing with her husband. Although dancing could be seen as being predominately a physical activity, she talked about it in a social context, whereby she was able to spend time with friends and socialise with others. During her first interview she was contemplating never being able to go dancing again:

'I can't dance now and I used to love dancing, ... he [husband] played in a dance band ... so I used to go you know with the band wives ... but I wouldn't be able to now' (Pt1.1; 21-29)

After taking part in the PR programme, this lady talked about plans to join a dancing group with a friend in the near future:

'we're gonna have a go at line dancing, at Christmas, well we're gonna start in the winter, I'm gonna go, [husband] will take us and we're gonna go round at the school and ehm and have a go a line dancing so that will be my dancing debut.' (Pt1.2; 123-125)

Therefore, the PR programme appeared to have impacted on her social life by giving her the confidence in her physical activities to join social activities such as dancing in the future.

\section{Discussion}

Whilst PR did not reduce these participants' levels of breathlessness, it changed the way they perceived and managed breathlessness, which impacted on both their physical and social engagement. Their perceptions of their exercise capacity increased, as did their confidence in dealing with dyspnoea when undertaking physical activities, thus lessening the experience of panic and anxiety. PR contributed to their perception of liberation from symptoms. This change could be attributed to a desensitisation to breathlessness - as suggested by clinical trials examining the effect of PR on exercise capacity and health status on people with COPD. 2,15,16 However, due to different methodological approaches, such studies cannot provide information on how patients' perception of their breathlessness changes.

Although there has been much debate on the usefulness of respondent validation in order to enhance credibility of findings in qualitative research, ${ }^{14,17,18}$ the authors wanted to ensure that the population from which the sample was drawn could see themselves in the identified themes. ${ }^{19}$ As such, identified themes were presented to groups of people with COPD who had taken part in a PR programme previously but who did not take part in this study. The comments made during these group presentations gave further insight into the effect of PR on breathlessness and activity in COPD. All of the participants felt that the findings presented at least in part their experience of PR and perception of the effects of the programme.

The themes presented here capture the effect of a PR programme on the experience of activity and perception of breathlessness for all participants. However, some of these aspects, such as the impact on breathlessness, appeared more important to some participants than others. This seems only natural, since participants would rate different aspects of both their lives and condition differently and therefore also attached different levels of importance to the impact of the PR programme.

The associated increase in perceived control and confidence, and lower levels of perceived panic, has been identified in previous studies ${ }^{20-23}$ and supports the findings presented here. Prior to PR, participants experienced anxiety and fear when breathless, and were worried about engaging in physical activities which might exacerbate their breathlessness. Fear of dying as a result of the experience of breathlessness has been found to affect adherence to exercise post-PR. ${ }^{24}$ Participants in this study felt more confident postPR in dealing with their breathlessness and therefore felt more confident in engaging in activities.

Little previous research has been published in relation to the effect of PR on household-related activities, but research on the impact of rehabilitation programmes for other chronic conditions has reported a perceived improvement in housework-related activities..$^{25,26}$ One study exploring the patient perspective on participation and attrition in PR found that activities related to personal care and housework were amongst patients' self-set treatment goals, ${ }^{27}$ indicating the importance of this area of activity to individuals with COPD.

The importance of social support as part of a rehabilitation programme in order to overcome feelings of social isolation has also been identified in previous research exploring the patient perspective of PR programmes 20,23 as well as rehabilitation for cardiovascular disease. ${ }^{28}$ However, findings presented here show that in some cases, the impact of PR on the experience of social activities not only enables patients to support each other, but also enables them to overcome feelings of social isolation. Wempe and Wijkstra ${ }^{29}$ stated that in order to prevent relapse post-PR, both physical and social activities need to be maintained, suggesting that social activities may be of equal importance to physical exercise in maintaining the benefits of PR. However, due to a lack of published research in this area, further studies are needed to 


\section{Discussion summary}

a) Difficulties encountered during this study: due to organisational changes within the NHS Trusts included in the recruitment strategy, recruitment was limited to one PR programme.

b) Alternative methodologies that would have been helpful in answering the research question: a mixed method approach may have allowed comparing and exploring of other aspects of the effect of PR on participants - such an approach may be useful for subsequent and larger studies.

c) New questions arising from the study: it would be of interest to explore the perceived long-term benefits of $\mathrm{PR}$, in particular in relation to social activities, using a mixed method approach.

d) Lessons for clinical practice as a result of the study: the effect of PR on perceptions of breathlessness is known to clinicians, but has not been published elsewhere; this study adds to our understanding of the impact of PR on individual experience of activity and may contribute to improved PR programmes by addressing patients' needs, in particular in relation to fear of activity.

explore the impact of PR on the experience of social activities long-term.

The effect of PR on the experience of physical activities such as mobility is supported by previous findings from both qualitative ${ }^{20,22,23}$ and quantitative studies. ${ }^{30,31}$ Previous qualitative studies involved only one interview post-PR, so no pre- to post- comparisons were possible. The longitudinal study presented here contributes to a greater understanding of how PR programmes affect the experience of physical activities in patients with COPD.

This study did not aim to explain cause and effect, but to understand how a PR programme affected the experience of activities from the patient perspective. One limitation of this study is the small number of participants $(n=8)$ who completed both pre- and post-PR interviews. Although this may have limited the opportunity for theoretical saturation, conducting two interviews with each participant provided rich data and allowed the researchers to explore issues related to the impact of PR in depth and over time.

The findings in this study relate to the short-term impact of PR on the individual experience of activity in COPD. It would be of interest to explore the perceived long-term benefits of PR, in particular in relation to social activities. A mixed method approach could integrate an in-depth exploration of how patients experience activities before and at different points after PR with a quantitative investigation into the link between physical and social benefits post-PR.

In conclusion, attending PR was associated with altered individual perceptions of breathlessness, which in turn had a positive impact on physical and social activity; post-PR, altered perceptions of breathlessness gave individuals increased confidence in dealing with their symptoms. Prior to PR, participants associated activities with breathlessness and panic, leading to a fear of activities; post-PR, individuals reduced this fear and felt able to increase their activities. This effect of PR on perceptions of breathlessness is known to clinicians, but to our knowledge has not been published elsewhere in the literature. This study adds to our understanding of the impact of PR on individual experience of activity and may contribute to improving programmes by addressing patients' needs.

\section{Conflict of interest declarations}

There are no conflicts of interest.

\section{References}

1. British Lung Foundation. Chronic Obstructive Pulmonary Disease . 2008.

2. Bestall JC, Paul EA, Garrod R, Garnham R, Jones RW, Wedzicha AJ. 2 Longitudinal trends in exercise capacity and health status after pulmonary rehabilitation in patients with COPD. Respir Med 2003;97(2):173-80. http://dx.doi.org/10.1053/rmed.2003.1397

3. British Thoracic Society $M$, et al. Pulmonary Rehabilitation. Thorax 2001; 56:827-34. http://dx.doi.org/10.1136/thorax.56.11.827

4. Nici L, Donner C, Wouters E, et al. American Thoracic Society/European Respiratory Society statement on pulmonary rehabilitation. Am J Resp Crit Care Med 2006;173(12):1390-413. http://dx.doi.org/10.1164/rccm.200508-1211ST

5. Katula JA, Rejeski WJ, Wickley KL, Berry MJ. Perceived difficulty, importance, and satisfaction with physical function in COPD patients. Health Qual Life Outcomes 2004;2(1):18. http://dx.doi.org/10.1186/1477-7525-2-18

6. Leidy NK, Haase JE. Functional performance in people with chronic obstructive pulmonary disease: a qualitative analysis. ANS Adv Nurs Sci 1996; 18(3):77-89.

7. Leidy NK, Haase JE. Functional status from the patient's perspective: the challenge of preserving personal integrity. Res Nurs Health 1999; 22(1):67-77. http://dx.doi.org/10.1002/(SICI)1098-240X(199902)22:1<67::AID-NUR8> 3.0.CO;2-D

8. Pitta F, Troosters T, Probst VS, Langer D, Decramer M, Gosselink R. Are Patients With COPD More Active After Pulmonary Rehabilitation? Chest 2008; 134:273-80. http://dx.doi.org/10.1378/chest.07-2655

9. Arnold E, Bruton A, Ellis-Hill C. Adherence to pulmonary rehabilitation: A qualitative study. Respir Med 2006;100(10):1716-23. http://dx.doi.org/ 10.1016/j.rmed.2006.02.007

10. Young P, Dewse M, Fergusson W, Kolbe J. Respiratory rehabilitation in chronic obstructive pulmonary disease: predictors of nonadherence. Eur Resp J 1999; 13:855-9

11. Glaser B, Strauss A. The Discovery of Grounded Theory. Chicago: Aldine, 1967.

12. Charmaz K. Grounded Theory. In: Smith J, Harre R, Van Langenhove L, editors. Rethinking Methods in Psychology. London: SAGE Publications, 2001: 27-49.

13. Mays N, Pope C. Qualitative research in health care. Assessing quality in qualitative research. BMJ 2000;320(7226):50-2. http://dx.doi.org/ 10.1136/bmj.320.7226.50

14. Mason J. Qualitative Researching. 2nd ed. London: SAGE Publications, 2002. 
15. Carrieri-Kohlman V, Douglas MK, Gormley JM, Stulbarg MS. Desensitization and guided mastery: treatment approaches for the management of dyspnea. Heart \& Lung 1993;22(3):226-34

16. Garrod R, Paul EA, Wedzicha JA. Supplemental oxygen during pulmonary rehabilitation in patients with COPD with exercise hypoxaemia.[see comment]. Thorax 2000;55(7):539-43. http://dx.doi.org/10.1136/thorax.55.7.539

17. Silverman D. Doing Qualitative Research - A Practical Handbook. London: Sage Publications Ltd, 2000.

18. Skeggs B. Situating the production of Feminist Ethnography. In: Maynard M, Purvis J, editors. Researching Women's Lives from a Feminist Perspective. London: SAGE Publications, 1994.

19. Chiovitti RF, Piran N. Rigour and grounded theory research. J Adv Nurs 2003: 44(4):427-35.

20. Camp P, Appleton J, Reid W. Quality of Life After Pulmonary Rehabilitation: Assessing Change Using Quantitiative and Qualitative Methods. Phys Ther 2000;80(10):986-95.

21. Harris D, Hayter M, Allender S. Improving the uptake of pulmonary rehabilitation in patients with COPD: qualitative study of experiences and attitudes. $\mathrm{Br} J$ Gen Pract 2008;58:703-10. http://dx.doi.org/ 10.3399/bjgp08X342363

22. Norweg A, Bose P, Snow G, Berkowitz M. A pilot study of a pulmonary rehabilitation programme evaluated by four adults with chronic obstructive pulmonary disease. Occ Ther Int 2008;15(2):114-32. http://dx.doi.org/10.1002/oti.251

23. Toms J, Harrison K. Living with Chronic Lung Disease and the Effect of Pulmonary Rehabilitation. Physiotherapy 2002;88(10):605-19.
http://dx.doi.org/10.1016/S0031-9406(05)60512-3

24. Rabinowitz MMC. Stories of exercise noncompliance among patients with chronic obstructive pulmonary disease after completion of pulmonary rehabilitation. Ph.D thesis, Adelphi University, US, 1999.

25. King KB. Emotional and fucntional outcomes in women with coronary heart disease. J Cardiovasc Nurs 2001;15(3):54-70.

26. Ripley S, Ronzio C, Cozad C, et al. Evaluation of a Multidisciplinary Rehabilitation Programme for Fibromyalgia: A Pilot Study. Todays Therapeutic Trends 2003;21(2):159-84

27. Fisher MJ, Scharloo M, Abbink JJ, et al. Participation and drop out in pulmonary rehabilitation: a qualitative analysis of the patient's perspective. Clin Rehab 2007;21:212-21.

28. Koivunen $\mathrm{K}$, Isola A, Lukkarinen $\mathrm{H}$. Rehabilitation and guidance as reported by women and men who had undergone coronary bypass surgery. Cardiovasc Nurs 2007;16:688-97.

29. Wempe JB, Wijkstra PJ. The influence of rehabilitation on the behaviour modification in COPD. Pat Educ and Counsel 2004;52:237-41. http://dx.doi.org/10.1016/S0738-3991(03)00097-1

30. Ngaage DL, Hasney K, Cowen ME. The functional impact of an individualized, graded, outpatient pulmonary rehabilitation in end-stage chronic obstructive pulmonary disease. Heart \& Lung 2004;33(6):381-9. http://dx.doi.org/10.1016/j.hrtlng.2004.08.003

31. Sewell L, Singh SJ, Williams JE, Collier R, Morgan MD. Can individualized rehabilitation improve functional independence in elderly patients with COPD? Chest 2005;128(3):1194-200. http://dx.doi.org/10.1378/chest.128.3.1194

Available online at http://www.thepcrj.org 
V Williams et al.

\section{Appendix 1}

\section{Interview schedule pre-PR:}

1. Tell me how your condition affects you on a daily basis?

2. How does your breathlessness affect you?

3. What does a normal day for you look like?

4. What activities do you engage in?

5. How does your condition affect these activities?

6. What is it that is important to you about these activities?

7. What do you enjoy about taking part/ engaging in these activities?

8. How does it make you feel being able (or being unable) to take part/ carry out these activities?

\section{Questions/ prompts post-PR interview:}

1. How are you feeling at the moment?

2. How does COPD affect you since you have taken part in the rehabilitation programme?

3. What has changed since last time I spoke to you?

4. Which particular aspects of your activities have changed?

5. How do you know feel about taking part in activities/ going out/ walking?

6. How do you feel about you breathlessness now? 